Pablo Federico Bianchi Becario Doctoral CONICET - Facultad de Ingeniería

Universidad Nacional de Cuyo (UNCuyo) -Instituto de Ciencias Humanas,

Sociales y Ambientales (INCIHUSA)

Consejo Nacional de Investigaciones Científicas y Técnicas (CONICET) Mendoza, Argentina https://orcid.org/0000-0001-994|-388| pfrbianchi@yahoo.com

\section{El Pabellón 24 de la Feria de América (1954): una aproximación en clave biográfica}

Pavilhão 24 da Feira da América (1954): uma abordagem biográfica

Pavilion 24 at the "Fair of the Americas" (1954): A biographical approach

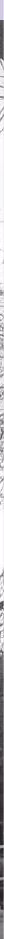

Figura 0 Mendoza. Pabellón 24 Vista actual. Fuente: Fotografía del autor.
Artículo resultado de la Tesis doctoral denominada "Arquitectura para el turismo en Mendoza (1900-1955): lectura histórica y análisis de sus representaciones sociales" Universidad de Mendoza, con financiamiento de CONICET 


\section{RESUMEN}

Realizada durante la segunda presidencia de Juan Domingo Perón en Mendoza, la Feria de América (1954) fue una exposición continental que buscó fomentar la producción regional y afianzar las relaciones comerciales e internacionales de Argentina con los países vecinos, además de ensalzarse como evento de atracción para visitantes y locales. Asimismo, se lució como espacio de competición internacional, dado que se presentaron a concurso stands de industrias, cámaras empresariales y cámaras de comercio. Concebidos como elementos de arquitectura efímera, los pabellones proyectados para la Feria enarbolaron los preceptos disciplinares propios de su momento. Trabajos de investigación recientes han buscado dar cuenta de la relevancia histórica y simbólica de este evento para la región, como también de los debates disciplinares que, en torno de la Arquitectura y del Diseño, suscitó este encuentro internacional. En este marco, el artículo pretende abordar el caso del único testimonio material de la Feria que se mantiene en pie, a partir una lectura crítico-analítica de la documentación de proyecto y de la obra como portadora de mensajes, considerando las trayectorias profesionales de los agentes técnicos involucrados con su ideación y materialización.

Palabras clave: exposiciones internacionales, edificios históricos, arquitectura efímera, trayectorias profesionales, arquitectura del poder.

\section{RESUMO}

Realizada durante a segunda presidência de Juan Domingo Perón em Mendoza, a Feria de América (1954) foi uma mostra continental que buscou promover as produções regionais e fortalecer as relações comerciais e internacionais da Argentina com os países vizinhos, além de ser elogiada como um evento de atração de visitantes e da população local. Da mesma forma, destacou-se como espaço de competição internacional, uma vez que foram apresentados a concurso stands de indústrias, câmaras empresariais e de comércio. Concebidos como elementos de arquitetura efêmera, os pavilhões projetados para a Feira levantaram os preceitos disciplinares típicos de sua época. Pesquisas recentes têm procurado dar conta da relevância histórica e simbólica deste evento para a região; bem como os debates disciplinares que, em torno da Arquitetura e do Design, provocaram este encontro internacional. Nesse contexto, o artigo visa abordar o caso do único testemunho material da Feira que permanece de pé, a partir de uma leitura crítico-analítica da documentação do projeto e da obra como portadora de mensagens, considerando as trajetórias profissionais dos agentes técnicos envolvidos em sua ideação e materialização.

Palavras-Chave: exposições internacionais, edifícios históricos, arquitetura efêmera, trajetórias profissionais, arquitetura de poder.

\section{ABSTRACT}

Held during the second presidential term of Juan Domingo Perón, in Mendoza, the Fair of the Americas (1954) took place. It was a continental exhibition that sought to promote regional production and strengthen Argentina's commercial and international relations with neighboring countries. It was also praised as an attractive event for visitors and locals. Likewise, it stood out as a space for international competition, given that stands from industries, business chambers, and chambers of commerce took part in the call. Conceived as elements of ephemeral architecture, the pavilions designed for the Fair displayed the disciplinary precepts typical of their time. Recent research has sought to account for the historical and symbolic relevance of this event for the region, as well as the disciplinary debates on Architecture and Design, that led to this international gathering. In this framework, this article aims to study the case of the only material testimony of the Fair that still stands, starting from a critical-analytical reading of the project documentation and of the architectural work as a messenger, considering the professional backgrounds of the technical players involved with its conception and materialization.

Keywords: International Exhibitions, Historical Buildings, Ephemeral Architecture, Professional Backgrounds, Government Architecture. 


\section{INTRODUCCIÓN}

La ciudad de Mendoza fue sede del certamen internacional conocido como Feria de América, un evento de carácter industrial que se llevó a cabo entre enero y abril de 1954. Como marco apropiado para la muestra, se dispusieron 30 ha en el perímetro del lago del Parque General San Martín, para albergar los cientos de stands y locales representantes de importantes comercios y agrupaciones industriales, como también pabellones de países latinoamericanos y de ministerios de rango nacional del gobierno argentino. La Feria corporizó el anhelo del gobierno nacional de mostrar una Argentina pujante, próspera, vinculada con los países de la región y a la vanguardia del desarrollo industrial.

La década entre 1946 y 1955 es considerada clave en la historia económica de la Argentina contemporánea. La producción nacional industrial cobraba una creciente relevancia en la matriz económica, orientada hacia una industrialización que requería -según los propósitos del plan peronista- el aliento del mercado interno, como han demostrado Claudio Belini (2009) y Pablo Gerchunoff, junto a Damián Antúnez (200I). Belini (2009) afirma que la promoción a la actividad industrial se enfocó en aquellas actividades que emplearan materias primas nacionales y estuviesen orientadas al mercado interno y hacia las manufacturas que elaboraran artículos de primera necesidad o de interés para la defensa nacional. En 1949, la Secretaría de Industria fue elevada al rango de Ministerio, incorporando bajo su competencia a las empresas estatales dedicadas a la extracción y refinamiento de hidrocarburos, como Yacimientos Petrolíferos Fiscales (YPF), pero también creando nuevas empresas estatales, como Agua y Energía o Gas del Estado.

Desde el ámbito del Diseño y la Arquitectura, la Feria encarnó una voluntad clara por exhibir los últimos avances en materia de construcción estandarizada, uso de estructuras en acero y madera, y provisión de equipamiento y mobiliario, entre los que destacaban, naturalmente, los de producción nacional. En palabras de Wustavo Quiroga (2012), la concreción de la Feria significó la amalgama de la industria, la política, la sociedad, el arte, la arquitectura y el diseño; en una acción de avanzada que logró "una propuesta vanguardista que, desde Mendoza, ponía al país en diálogo con las tendencias internacionales" (p. 13). El carácter efímero de los edificios de la Feria abrió la posibilidad de experimentar con otros materiales, determinados por el mismo reglamento de construcciones de los pabellones y stands (Raffa y Marchionni, 20 I I), que estaba dirigido al montaje en seco y al diseño estructural de elementos livianos, la reducción de los tiempos de ejecución, facilidad y rapidez en el ensamblaje de las piezas o partes, la racionalización del proceso de fabricación (que redundaba en una mayor economía al controlar el desperdicio de material) y la posibilidad de reutilización de las estructuras y componentes una vez terminada la exposición.

El presente artículo adhiere a una vertiente que problematiza el objeto arquitectónico y sus características, vinculándolo con las trayectorias profesionales de los técnicos y las agencias de las que emanaban los proyectos. Esta mirada, complementaria de los estudios tradicionales centrados sólo en la obra de arquitectura, ha suscitado un creciente interés en la comunidad científica y académica de Argentina y Latinoamérica, que se aprecia en trabajos señeros en esa misma línea de investigación (Articardi, 20 l 6; Cirvini, 2004; Jajamovich, 20 I I; Liernur, Aliata, Crispiani y Silvestri, 2004; Pintus, 20 I4; Raffa, 2019; Raffa, 2017; Raffa y Cirvini, 2013; Verde, 2002). 
La particular manera de abordar la producción de arquitectura, permite delinear el derrotero de conflictos y acuerdos generados en torno del campo disciplinar', desde la experiencia de los actores involucrados y sus organismos de pertenencia, como un modo de comprender las formas de pensar la arquitectura, derivados del contexto social, económico y cultural propio de la época.

En cuanto a los aspectos metodológicos, el trabajo adhiere al "modelo narrativo histórico" (Sautu, Boniolo, Dalle y Elbert, 2005) y al "estudio de casos" (Stake, 1998) para el análisis del ejemplo seleccionado. Puntualmente, desde el ámbito de la arquitectura, Bruno Zevi (1998) y Marina Waisman (1993) constituyen los referentes a la hora de encarar el análisis objetual atravesado por los procesos de evolución histórica, que involucra factores sociales, políticos, económicos y de la cultura arquitectónica. Waisman profundiza en el estudio de la arquitectura y la ciudad desde la mirada latinoamericana. Esta conceptualización otorga valor a las producciones de la cultura material consideradas "modestas" por los lineamientos tradicionales eurocentristas. La autora propone un análisis desde el entorno y el contexto de emergencia de estas arquitecturas. En este sentido, desarrolla tópicos referidos al rescate de las técnicas y saberes del pasado y la lectura del "edificio como documento histórico" (1993, p. 137), como también de la arquitectura en su función comunicativa, al instituirse como portadora de mensajes (Eco, 1986). Por este motivo, la observación directa de la obra (Piovani, 2010) conforma una de las técnicas de abordaje.

Para Zevi (1998), la interpretación de la arquitectura parte de la consideración del espacio, tanto el interior como el exterior que la contiene. Además, sostiene que es posible "leer" desde la disciplina componentes vinculados con su contenido, con su forma y con la percepción sensible (1998, p. 27).

\section{El contexto histórico}

El fuerte impulso del Estado al acceso al bienestar social, promovido en el contexto del primer peronismo, fue otorgando una cualidad móvil a la sociedad. A partir de 1946, cobró forma una nueva edición de este proyecto ascensional, que había acompañado la trayectoria del país desde los albores del siglo. En ese marco, y de acuerdo con Juan Carlos Torre y Elisa Pastoriza (200 I), "más argentinos pudieron mirar a los que estaban situados arriba de ellos en la escala social con la expectativa de que en poco tiempo ellos o sus hijos habrían de alcanzarlos" (p. 278). Las ventajas gremiales que regulaban la jornada laboral y las vacaciones pagas constituyeron el primer paso en el proceso de democratización del bienestar, lo que permitió que muchas de las prácticas que anteriormente estaban reservadas a los miembros de la aristocracia y la dirigencia política, permearan a estratos más amplios del entramado social. En concreto, esta mayor movilidad fue posible por una estructura de ingresos más igualitaria. Y, con más ingresos disponibles, "los argentinos pudieron consumir más y en forma más variada" (Torre y Pastoriza, 200 I , p. 282). En consecuencia, se observó un aumento marcado en los niveles de vida de la población, particularmente de los estratos populares.

A nivel provincial, la gestión de Faustino Picallo (1946-1949) otorgó un fuerte impulso a la Fiesta de la Vendimia, organizando exposiciones anuales de industria, comercio y minas. Cecilia Raffa (2018) ha puntualizado que los gobiernos de Blas Brísoli (1949-1952) y Carlos Evans (1953-1955) implementaron el Primer y

1 Este trabajo adhiere a las conceptualizaciones de "campo", "habitus", "capital" y "estrategias" desarrolladas en la Teoría de la acción de Bourdieu

(1999). 
AS / Vol $40 / \mathrm{N}^{\circ} 61 / 2022$
El Pabellón 24 de la Feria de América (1954):

una aproximación en clave biográfica

Pablo Federico Bianchi

102-117
Segundo Plan Quinquenal Provincial, con ejecución de obra pública (centros de salud, hospitales, salas de maternidad, ayuntamientos municipales, escuelas y sedes de policía), construcción de hoteles populares de turismo en los departamentos de la campaña (como San Rafael, Tunuyán y Tupungato) y promoción de actividades orientadas al esparcimiento masivo, como el cine, espectáculos deportivos y turismo. Mendoza fue presentada como una provincia pujante, consolidada sobre la base de un binomio virtuoso: como territorio productivo y como destino turístico².

Raffa (20 I 8) explica que, dentro del repertorio de políticas nacionales de promoción e inversión nacional que tuvieron a Mendoza como destino, se destacan, por un lado, la visualización lograda "a través de las sucesivas Fiestas de la Vendimia (...), así como también los actos y obras relacionados al Año del Libertador; por el otro, la construcción de la villa fronteriza de Las Cuevas" ( $p$. 197). Las ferias industriales celebradas en la provincia (especialmente la Feria de América) sirvieron para la difusión de las acciones de gobierno.

\section{Los debates en torno de la arquitectura}

En términos generales, la arquitectura a partir de 1940 manifiesta el abandono paulatino de los rasgos de austeridad, abstracción y masa, para comenzar su búsqueda entre los valores de la elocuencia, materialidad y transparencia, según apunta Francisco Liernur (200 I). La mirada hacia Europa viró en la segunda posguerra hacia Estados Unidos: las revistas alemanas de los años previos a 1940 fueron reemplazadas por The Architectural Forum y Progressive Architecture. De esta manera, sobre todo luego del triunfo aliado, la vida cotidiana "recibió en avalancha el impacto del american way of life, por intermedio de los magazines y el cine" (Liernur, 200 I, p. 230).

En este momento, el trabajo profesional experimentó una transformación notable que se manifestó en el desplazamiento del modelo de la actividad liberal individual a favor de la instalación de un nuevo sujeto grupal, tanto en el ámbito estatal como en el privado. Como organismo del Estado, la Dirección Nacional de Arquitectura (DNA) "centralizó la planificación, proyecto y ejecución de la obra pública del gobierno nacional y de los planes quinquenales" (Cirvini, 2004, p. 248).

Como bien expresa Liernur (200 I), surgió en este momento una nostalgia por lo individual, lo primitivo, lo natural, lo privado, que fue especialmente promocionada por sectores nacionalistas (p. 240). La manifestación más elocuente de esta reacción fue, en el ámbito de la arquitectura, la difusión masiva del gusto "rústico" y las referencias al organicismo y el regionalismo. De larga tradición en Estados Unidos, la protesta antiurbana se introdujo por dos vías principales en la cultura argentina: una, desde la difusión de la obra de Frank Lloyd Wright. Otra, gracias a la obra de Richard Neutra: la revista Nuestra Arquitectura comenzó a dedicar desde entonces un importante espacio a esa arquitectura norteamericana, difundiendo trabajos del propio Neutra, de Breuer, de Rafael Soriano (Liernur, 200 I). Pero el acercamiento a la naturaleza contaba también "con otros modelos, italianos o brasileños" (Liernur, 200 I, p. 242).

Estas condiciones actuaron como caldo de cultivo de una arquitectura que, si bien surgió de un espacio de reflexión en torno de las particularidades de su 
cualidad "moderna", también logró identificarse con las tradiciones y materiales locales. En paralelo, se hizo notoria la preferencia por materiales no industriales, lo que provocó un "redescubrimiento" del ladrillo visto o la piedra. A estas consideraciones se sumaron las procedentes de la teoría del espacio, traídas por Erwin Walter Palm, que visitó Buenos Aires en 1950, y por Bruno Zevi, que lo hizo en 1951. El espacio constituía una de las preocupaciones centrales en el debate de las artes figurativas, particularmente en aquellos grupos afines al movimiento del arte abstracto (Liernur, 200 I).

Los "concretos", como Alfredo Hlito o Tomás Maldonado, "buscaban reflexionar sobre la relación entre plano y espacio, pasando de la negación absoluta de éste a la exploración de construcciones espaciales a partir del color y la línea" (Liernur, 200 I, p. 285). La referencia más importante la constituía el neoplasticismo y el suprematismo, mediados en esos años por la lectura de Lazlo Moholy Nagy. Premisas como excelencia tecnológica, depuración lingüística e intransigencia funcional conformaron el sustento de esta corriente. A ella adhirieron César Jannello y Gerardo Clusellas, a cargo de la Oficina de Arquitectura y Planeamiento, "responsable de concebir la imagen general de la Feria de América y de sus pabellones" (Quiroga, 2012, p. 29).

\section{Los proyectistas: trayectorias profesionales antes y después del Pabellón 24}

Roberto Quiroz (1915-s.f.) se graduó de Arquitecto por la Universidad de Buenos Aires (UBA), en junio de 1938. Junto al arquitecto Carlos A. Quiroz, obtuvo en 1939 el primer premio del Concurso para el Palacio de la Legislatura de Catamarca. Con Eduardo Naón Rowland proyectó viviendas particulares en el suburbio norte de la Ciudad de Buenos Aires. En todas ellas emplearon el ladrillo a la vista. José M. Vedoya Green lo acompañó en el proyecto de una vivienda rural mínima, en la que, a partir de recursos "excesivamente reducidos", se constreñía a los proyectistas dentro de límites tan estrechos "que no ha quedado margen para realizar obra arquitectónica, más allá de la bondad de la planta y la racionalidad de la estructura" (Tres casas suburbanas, 1945, p. 91). Proyectaron, además, otra en Olivos, donde exploraron los recursos de la estandarización, la racionalidad de la estructura y la expresividad del ladrillo.

Quiroz trabajó en la Dirección de Arquitectura del Ministerio de Obras Públicas (MOP) de la Nación. Desde esta repartición proyectó la sede de la Fundación Eva Perón, luego Facultad de Ingeniería (1950-1957). Aparte de su actuación en la oficina de arquitectura pública, se desempeñó entre 1945 y 1968 como socio del estudio Roberto Quiroz- Ismael Gil Chiappori³. Juntos abordaron la remodelación del estadio Luna Park en 1951 y el barrio "I7 de Octubre" (Villa Pueyrredón, Ciudad de Buenos Aires). Como proyectistas del estudio, resolvieron numerosos edificios en propiedad horizontal, "de los cuales destacan el de calle Arenales 3605, esquina Julián Álvarez (1957) y el de calle Araoz 2725 (1959)" (Quiroz, s.f.).

Es posible que su desempeño en el pabellón para el MOP de la Feria de América, le reportase la experiencia necesaria para proyectar el pabellón argentino de la Exposición Internacional de Osaka, Japón en 1970 (Pabellón Argentino, 1970). En 1973 abordó el encargo para el Casino de Necochea

3 Chiappori nació en 1908 y se graduó en Arquitectura por la UBA, en 1932. Desde 1940 hasta 1949 se desempeñó en la DNA. Entre 1962 y 1969 fue Director Nacional de Arquitectura (Fiorito, 2012). 
Figura 1 Roberto Quiroz en una visita a las obras del casino de Necochea, acompañado por autoridades y cronistas. Fuente: Flores (2014, p. 7).

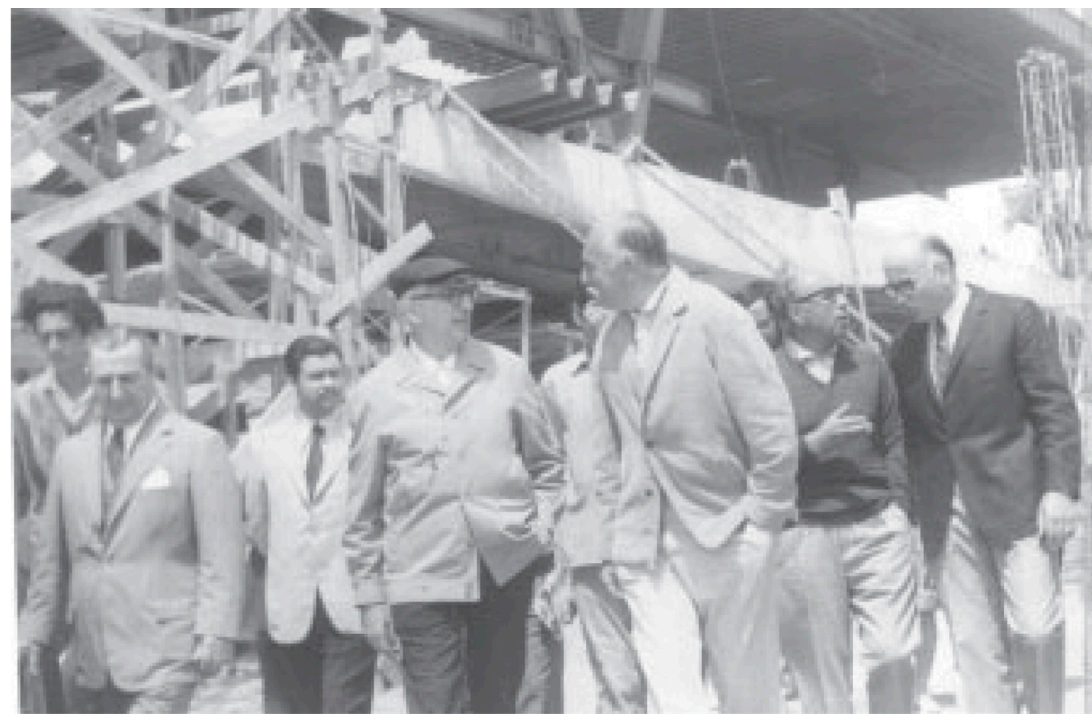

(Figura I), oportunidad en que reflexionó sobre nuevos caminos vinculados a la experimentación plástica, a través de grandes volúmenes resueltos en hormigón armado, sin dejar de lado los beneficios de la estandarización y la racionalidad en el diseño, y recurriendo a elementos premoldeados, también en hormigón.

Luis María Mamerto Bianchi (1912-1998) nació en Tandil (provincia de Buenos Aires) y cursó sus estudios universitarios en la Facultad de Arquitectura de la UBA, con título expedido en 1937. En 1936, realizó un viaje a Europa con el profesor Real de Azúa. Estuvo en Alemania durante los Juegos Olímpicos, luego en Francia y en Italia. El mismo año "ganó una medalla de oro en concurso estímulo organizado por la Sociedad Central de Arquitectos (SCA). Había ingresado como socio aspirante a la SCA en julio de 1935 y participó activamente en diferentes comisiones" (Fiorito, 2012). Recibió numerosos premios derivados de su actuación en concursos (entre 1936 y 1955). En ocasión de recibir el premio por la Comisión Nacional de Cultura y el V Salón Nacional de Arquitectura, para el Aeropuerto de la Ciudad de Buenos Aires, manifestó:

sería para mí el mayor premio que pudiera lograr como ciudadano argentino, que se viera convertida en realidad la construcción en Buenos Aires de la obra del aeropuerto y, en consecuencia, poseer en nuestra ciudad uno de los campos de vuelo más importantes del mundo (El progreso de Buenos Aires reclama un gran Aeropuerto, 1943, s.p.)

La expresión vertida en la crónica daba cuenta del pensamiento que juzgaba favorablemente la relación entre técnica y sociedad, propia de ese momento. Bianchi ejerció como Director del Plan Regulador de Olavarría, en 1957. Asimismo, participó como miembro de los equipos de "planes reguladores de Chivilcoy, Tigre, Chascomús y Luján, en la provincia de Buenos Aires" (Curriculum vitae Luis María Bianchi, 20 I5, s.p.).

Fue miembro fundador de la Asociación Argentina de Planeamiento y docente de las asignaturas Composición Urbanística, Urbanismo y Planificación y Planeamiento, en la Facultad de Arquitectura de la UBA, 


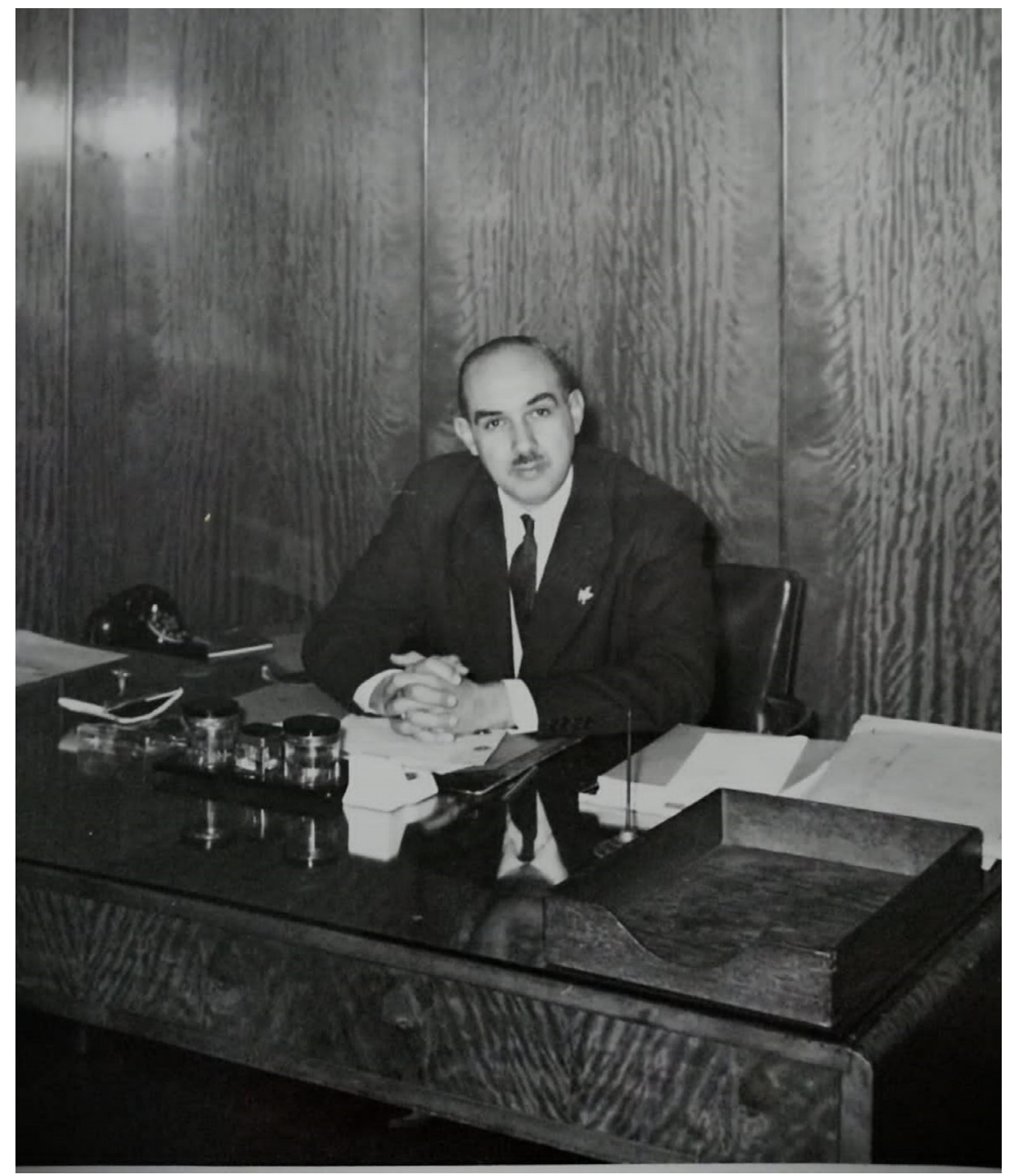

Figura 2 Luis María Bianchi en su despacho del MOP. Fuente: repositorio familia Bianchi.

entre 1951 y 1973. Su constante formación y perfeccionamiento profesional lo convirtieron en urbanista y, específicamente, en un paisajista de gran sensibilidad.

Su vinculación con la agencia estatal de arquitectura se inició cuando cursaba cuarto año de la carrera, momento en que ingresó al MOP. Fue becario de la Organización de Estados Americanos, reconocimiento que le permitió realizar un viaje de estudios a las New Town inglesas (1955). En la función pública se desempeñó como Jefe de Departamento de la DNA (Figura 2) y como miembro de la comisión de obras de sistematización y urbanización de la Ribera Norte, Secretaría de Obras Públicas (1967). Junto con trabajar para el Ministerio, fue socio de Luis Vitores (quien lo había acompañado en la comisión del Plan para Olavarría), y ejerció como "protesorero, bibliotecario, vocal de la comisión directiva y miembro del colegio de jurados de la SCA" (Fiorito, 2012). Entre 1962 y 1968 ocupó el cargo de Director del Instituto Superior de Urbanismo. Bianchi viajó a Inglaterra y Holanda en 1965 "para participar como becario en un estudio sobre planeamiento y urbanismo y, en 1967, a Toronto en representación de la Facultad de Arquitectura y Urbanismo, al Congreso de Áreas Metropolitanas" (Curriculum vitae Luis María Bianchi, 20 I5, s.p.). 

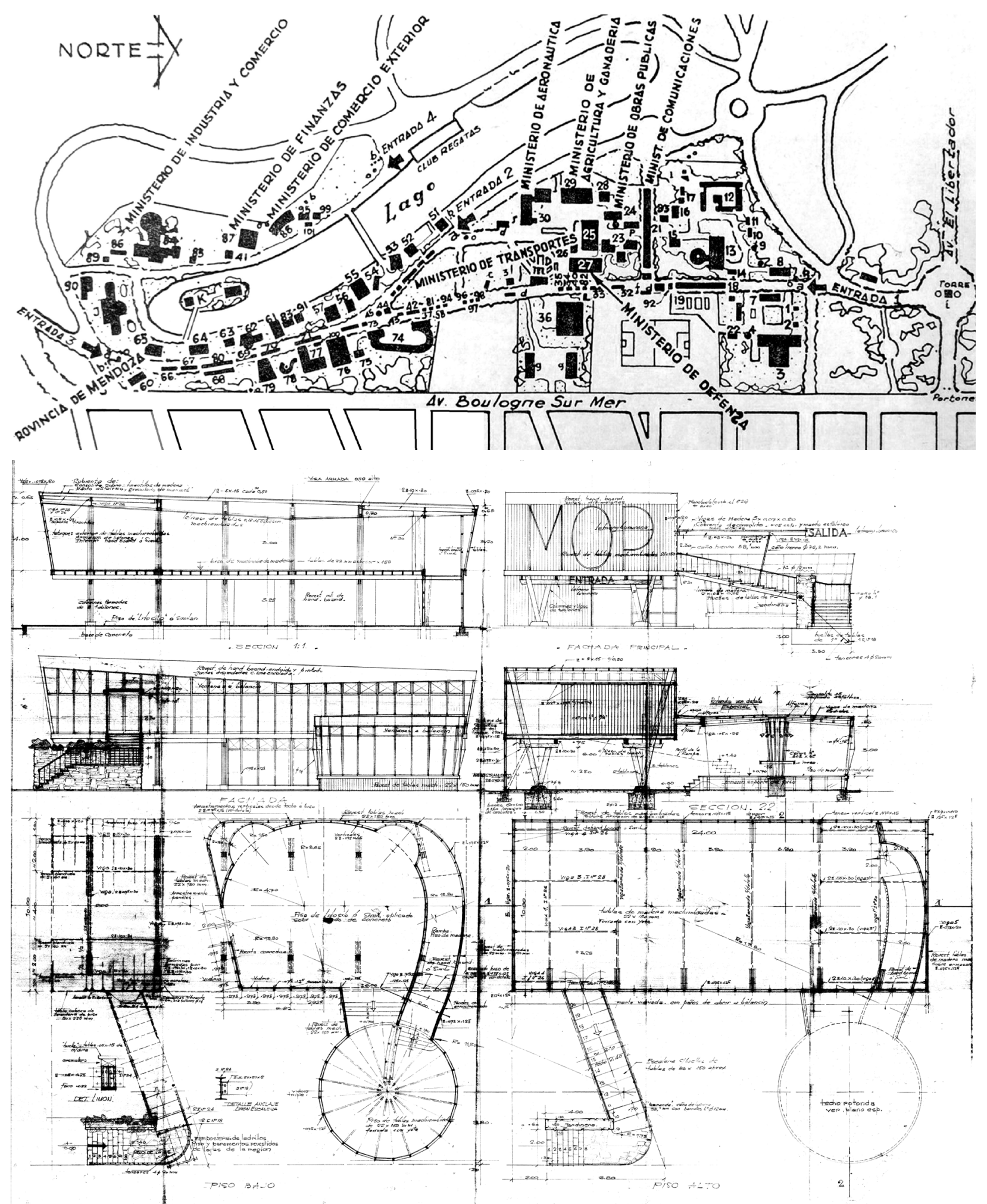

Figura 3 Plano general de

la Feria de América. Fuente:

Mendozantigua [Blog] (https://

mendozantigua.blogspot.com/)

Figura 4 Mendoza. Pabellón

MOP para Feria de las Américas.

Plano General. Fuente: Archivo

CeDIAP-AABE. 


\section{El Pabellón 24- Ministerio de Obras Públicas de la Nación}

La Feria de América demandó la construcción de 93 pabellones y casi 20 dependencias, incluyendo la Torre Alegórica, un teatro al aire libre y bares. Los países americanos que tenían representación (y pabellones) fueron Brasil, Chile, Ecuador y Paraguay. También hubo un gran pabellón que albergó distintos países latinoamericanos, stands de empresas chilenas y mendocinas y pabellones provinciales para Mendoza, San Juan, Misiones, La Rioja, Eva Perón (actual La Pampa), Córdoba, Corrientes, Santa Fe,Tucumán y Buenos Aires, además de stands y locales para diversas cámaras comerciales (Quiroga, 20 I2).

Un gran espacio vacío en los prados del Parque articulaba, a modo de plaza, los pabellones del Ministerio de Aeronáutica (en el extremo Sur), del Ministerio de Agricultura y Ganadería, de la Universidad Nacional de Cuyo y del Ministerio de Obras Públicas de la Nación (al Norte). El pabellón del Ministerio de Transporte, al Este, cerraba virtualmente este espacio (Figura 3). El edificio del MOP es el único testimonio en pie de la Feria de América. Si bien la tradición oral sostiene que fue el stand de Cuba, este error se debe a que "albergó por mucho tiempo una boite con ese nombre", luego de desmontada la exposición, pero la asignación dada en el Master Plan "es irrefutable, como también lo es la lista de referencias que da cuenta de la existencia del stand cubano dentro del pabellón de Países Latinoamericanos" (Bórmida, 2012, pp. 217, 218).

El pabellón 24 se componía de dos volúmenes abstractos, de formas contundentes, vinculados por una circulación orgánica, que combinaba rampas y escaleras (Figura 4). El primer volumen, elevado $3 \mathrm{~m}$ del nivel del suelo y concebido como paralelepípedo rectangular, se apoyaba en un sistema de pares de columnas en $\vee$, trabadas con las vigas del entrepiso y de la cubierta. Todos los elementos resistentes estaban resueltos en madera, a excepción de las vigas de las secciones extremas del techo, donde la escasa altura impedía desarrollar vigas reticuladas, por lo que se optó por perfiles IPN. Bajo este cuerpo y en la mitad Sur, dejaba un espacio a modo de atrio semicubierto, que oficiaba de transición entre el exterior y el interior. En la mitad Norte cobijaba el salón de exposiciones de la DNA que, por medio de una doble línea de tabiques de madera, a partir del manejo geométrico de arcos de círculos de gran plasticidad, resolvía los tabiques exteriores e interiores, revestidos con listones de machimbre. Un gran ventanal hacia el Este proponía la única conexión visual con el prado. Con un carácter meramente expositivo, este espacio exhibía maquetas y láminas de proyectos de la Dirección, como el Asilo San Miguel, edificio de YPF, la Escuela Nº6 de Santiago del Estero, el Hotel Turismo de Bariloche y la Hostería Embalse, entre otros, lo que denota la diversidad de programas, tipologías y escalas que manejaba la agencia estatal (Figura 5).

Luego se accedía al volumen de circulación o "rotonda" que configuraba el contrapunto compositivo del bloque más alto (Zevi, 1998). La rotonda tenía forma de cilindro, con paramentos levemente inclinados hacia afuera y una cubierta resuelta con vigas radiales soportadas por doce caños de acero, que conformaban un óculo central (Figura 6).

El volumen principal, desplegado en la cota $+3,25 \mathrm{~m}$, albergaba un gran espacio de exposición de planta libre, donde se alternaban mesones de dibujo 


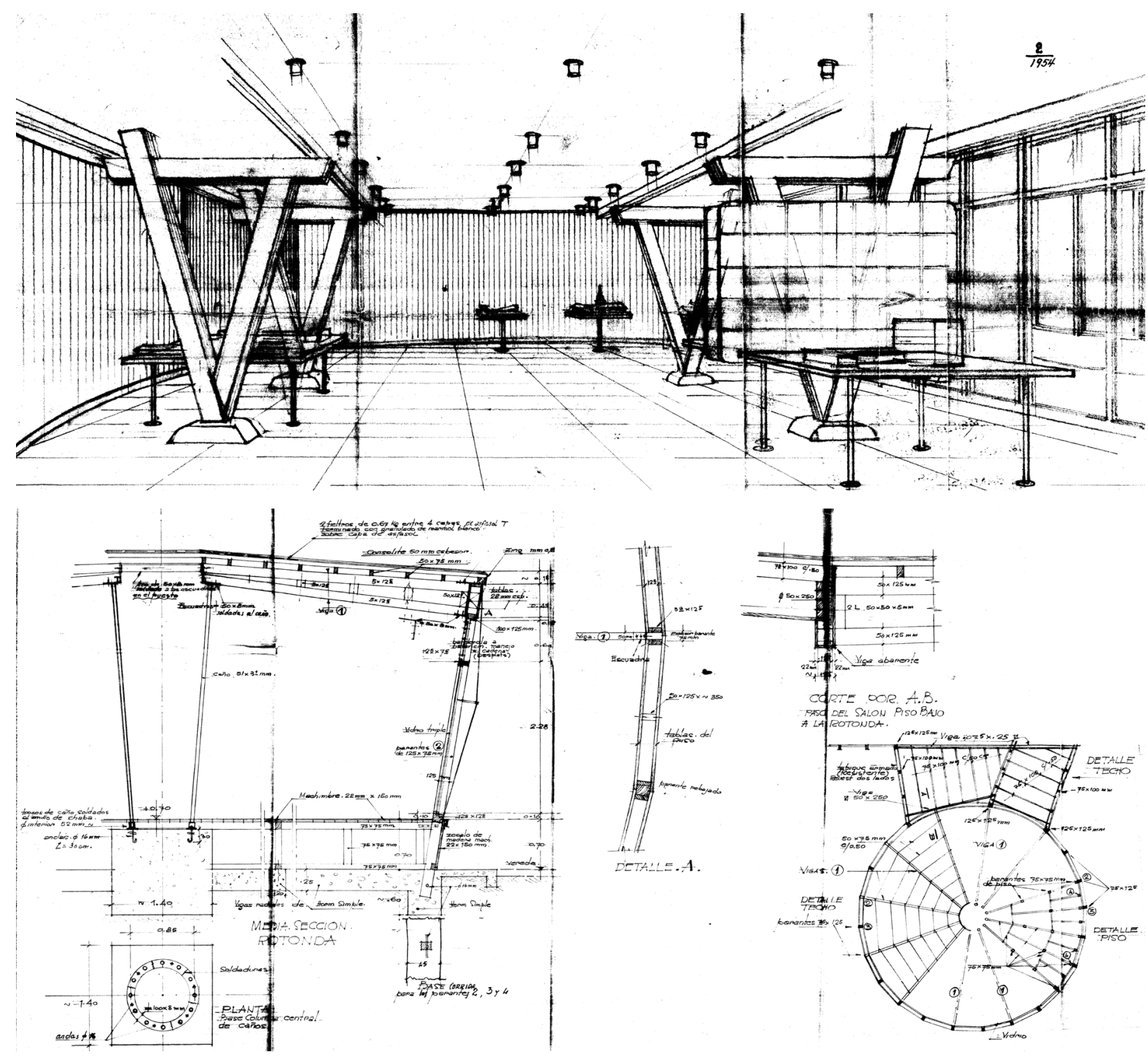

Figura 5 Salón DNA.

Perspectiva. Fuente: Archivo CeDIAP-AABE.

Figura 6 Detalle de la rotonda del Pabellón 24. Fuente: Archivo CeDIAP-AABE. técnico, maquetas de proyectos y paneles expositivos en los muros. El egreso del pabellón se hacía por el extremo Sur, vinculando simbólicamente los puntos inicial y final del recorrido (Zevi, 1998), por medio de una escalinata en dos tramos, el primero de ellos cubierto por una extensa marquesina en voladizo, soportada por dos barras de acero.

Las fechas consignadas en los rótulos de los distintos planos confirman que el proceso de proyecto del edificio se extendió de octubre a diciembre de 1953. Los rótulos revelan los nombres de otros agentes técnicos de la repartición, involucrados en la confección de la documentación de obra: el plano de estructura de la rotonda fue firmado por un agente de apellido Caddia, Soto figuraba como responsable del dibujo general y de detalle del rubro arquitectura; R. Bejar aparecía como responsable de la instalación eléctrica, con su dibujante (de nombre ilegible); y A. Peretti como responsable del dibujo de los artefactos de iluminación, que habían sido diseñados por los mismos proyectistas. Los planos generales y de detalle dan cuenta del carácter integral del proceso de diseño que abordó, asimismo, los elementos de equipamiento fijo, como mesas para 

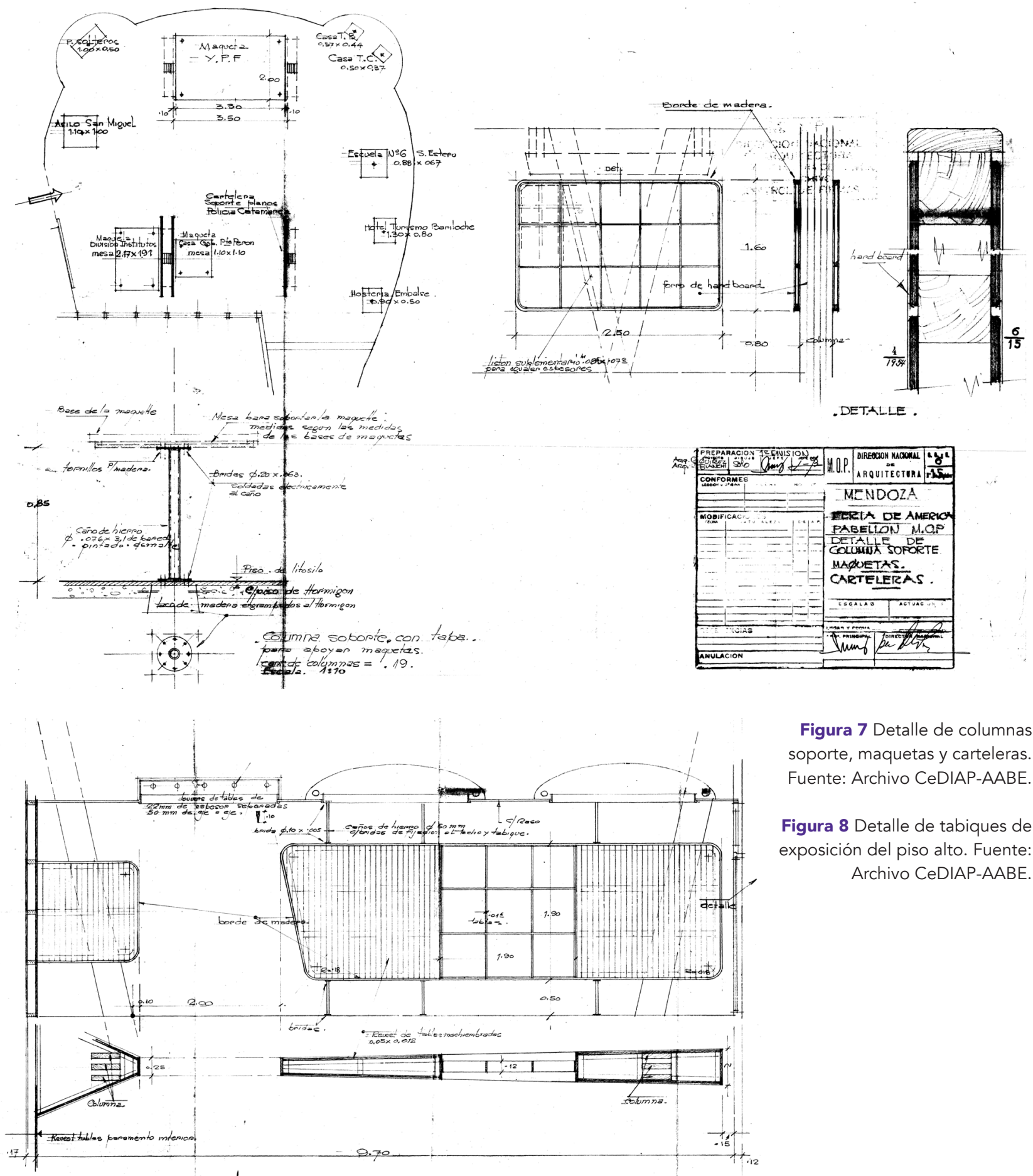

Figura 7 Detalle de columnas soporte, maquetas y carteleras. Fuente: Archivo CeDIAP-AABE.

Figura 8 Detalle de tabiques de exposición del piso alto. Fuente: Archivo CeDIAP-AABE.

exposición de maquetas, paneles y tabiques de apoyo de carteleras (Figuras 7 y 8).

El planteo estructural es una de las características más interesantes del pabellón, connota la intención vanguardista de los autores y la madurez con que afrontaron el encargo, en el que cristaliza parte de la experiencia previa de ambos: racionalidad, empleo de secciones comerciales estandarizadas, economía de recursos y simplicidad en el montaje y ejecución, expresado en el uso de uniones abulonadas o atornilladas. En la resolución material predominó la simplicidad y la rapidez: en paramentos se emplearon paneles hardboard, el piso de planta baja 
se ejecutó en Litosilo y el de planta alta con tablas de madera machimbradas. La "observación directa" del edificio (Piovani, 2010) confirma una cuidada factura y excelente calidad de los materiales, otro de los rasgos salientes de la obra, aun cuando había sido concebida como una construcción efímera.

La revisión de la documentación disponible en el archivo del Centro de Documentación e Investigación de la Arquitectura Pública [CeDIAP] y de la fotografía histórica de la maqueta, proveniente del mismo repositorio, permite comprender la resultante volumétrica-espacial del objeto arquitectónico: el pabellón se concibió con un alto grado de abstracción (Zevi, 1998). Por medio de sutiles estrategias de operación sobre la forma, se acentuaba el carácter singular del edificio: la leve inclinación hacia afuera de los muros extremos del paralelepípedo proponía una lectura de "cinta" continua, cuyos elementos podían asumir tres funciones espaciales: plano de piso y de techo (según se hallase en posición horizontal) o cerramiento (en posición predominantemente vertical). Esta envolvente continua no admitía aberturas, sino que, en la lógica compositiva del objeto, la vocación de "mirar" al exterior se asumía en las fachadas largas, orientadas en sentido Oeste-Este. Esto permitió adosar a la fachada del acceso, hacia la plaza en dirección Sur, el letrero MOP identificatorio del pabellón, en luces de neón ocultas tras esbeltas letras de chapa plegada, desarrolladas en la altura completa del bloque suspendido.

Desde las interpretaciones "fisio-psicológicas" propuestas por Zevi (1998), la composición connota un juego antitético entre el bloque horizontal, elevado, vinculado con lo racional y lo imperecedero, que contrasta con la volumetría de la rotonda, asociada al dinamismo, la hesitación y lo transitorio, logrando un equilibrio de fuerzas constitutivas que dieron origen a un edificio de gran calidad expresiva y formal, que se insertó de manera armoniosa en el paisaje. Por otra parte, los juegos de luces y sombras que generaban matices en distintas horas del día, provenientes del follaje de los árboles presentes en el sector, en contrapunto con la profusa iluminación que emanaba del interior del volumen acristalado en horario nocturno, debieron configurar vistas muy sugerentes para los visitantes.

La única referencia que la construcción hace de lo "local", la constituye el basamento de la escalinata de salida, dado que se materializó en piedra natural labrada y asentada con mezcla, apelando a la cualidad "rústica" y de arraigo al lugar, aun cuando se trataba de una arquitectura altamente eficiente y racional.

Es posible que los antecedentes de Bianchi en el manejo del paisaje hayan influido a la hora de imaginar la vinculación con el entorno verde predominante del Parque, desde el espacio semicubierto del atrio de acceso, pasando por los salones de exposición y hasta la llegada al pie de la escalinata, posterior a la salida. En el caso de los aventanamientos del bloque suspendido, estos permitían el ingreso de luz rasante desde el Oeste y una visual fluida del bosque hacia el Este, lo que manifiesta una concepción de la obra de carácter dialógico, a caballo entre la idea del "mirador" y la del "objeto a mirar".

\section{REFLEXIONES} FINALES
La Feria de América representó una oportunidad destacadísima que permitió visibilizar la producción industrial argentina y estrechar lazos comerciales con los países y cámaras de comercio e industria participantes, a la vez que se instauró como vidriera de la arquitectura y el diseño argentino y latinoamericano.

El abordaje analítico del único edificio subsistente de esa exposición, desde las 
trayectorias profesionales de sus autores, posibilitó ahondar en las particularidades del proyecto arquitectónico en contraste con los debates disciplinares al interior del campo, que permeaban desde las revistas de arquitectura, las reuniones y conferencias internacionales, la visita de personajes destacados o los viajes que algunos agentes realizaban, como parte de su proceso formativo o profesional.

Las condiciones singulares del ejercicio proyectual discurrieron entre la adopción del lenguaje, en que predominaba una voluntad explícita orientada a la abstracción; la definición del sistema constructivo-estructural, donde la geometría del sistema portante adquiría relevancia superlativa en la resolución del proyecto; y el planteo espacial, que respondía a una necesidad meramente funcional (en este caso, expositiva). Esta necesidad impuesta por el programa del edificio no socavó los sustentos simbólicos de la obra, muy por el contrario, hizo alarde de una relación armoniosa con el medio, receptiva de las cualidades paisajísticas propias del lugar y atenta a la componente sensible propuesta por las secuencias afueraadentro-afuera y acceso-recorrido-ascenso-recorrido-salida-descenso. En este sentido, la valoración del tiempo como duración del itinerario propuesto, pero también del tiempo transcurrido en la naturaleza, donde se involucran los colores y la luz de los prados del Parque, evocan la componente "rústica" del edificio y su apego a la condición de lo "local".

Las trayectorias profesionales de los proyectistas evidencian una vocación constante por la innovación y la experimentación. La multiplicidad de problemas y de escalas que abordaron nutrió sin duda sus modos de pensar la arquitectura, lo que les valió el reconocimiento de sus pares y de las agencias estatales en que se desempeñaron.

La aproximación a los procesos de ideación del edificio, pero también a su contexto de emergencia, permite, en primer lugar, arriesgar algunas consideraciones que complementan la mirada convencional de la arquitectura del período, para dar paso a una visión que atiende los condicionantes particulares de un modo de diseñar, de construir y de comunicar, de una dirigencia política cuyo propósito era mostrar la capacidad ejecutiva del Estado. En un segundo plano de análisis, esta exploración conduce, igualmente, a comprender la ideología de esa dirigencia política. Por este motivo, la componente retórica del diseño se instituyó como elemento central, lo que explicaría la indagación en materiales alejados de la supremacía del hormigón armado, la búsqueda de economía y pureza de la propuesta y la estandarización y la altísima calidad en el diseño y ejecución. A estos principios responden la contundencia y claridad conceptual de la arquitectura efímera desarrollada en la muestra y, en particular, del Pabellón 24, como resultante directa del proceso de innovación y experimentación precedentemente aludido. Aún más, este espíritu de superación no puede leerse aisladamente, sino que debe examinarse dentro de un posicionamiento más amplio, proveniente de la dirigencia, que abrazó una idea de progreso ilimitado, derivado de la creciente industrialización, como parte de un plan general que buscó fortalecer las economías provinciales y la satisfacción de las demandas del mercado interno argentino. 
Belini, C. (2009). La industria peronista. Buenos Aires: Edhasa.

Bórmida, E. (20 I2). Pabellón 24. Ministerio de Obras Públicas de la Nación. Vestigio visible. En Quiroga,W. (Ed.), Feria de América: vanguardia invisible (pp. 212 225). Mendoza: Fundación del Interior.

Bourdieu, P. (1999). Razones prácticas. Sobre la teoría de la acción. Barcelona: Anagrama.

Cirvini, S. A. (2004). Nosotros los arquitectos: campo disciplinar y profesión en la Argentina moderna. Fondo Nacional de las Artes. Mendoza: Zeta.

Curriculum vitae Luis María Bianchi ( $14 /$ | |/20 I5). Programa IBERARCHIVOSADAI. CEDODAL

Recuperado de en https://issuu.com/cedodal/docs/arqs I-Imb3-cv_luis_maria_ bianchi

Eco, U. (1986). La estructura ausente. Madrid: Ed. Lumen.

El progreso de Buenos Aires reclama un gran Aeropuerto (0 // 2/ 1943). Crítica, Buenos Aires, s.p. Recuperado de https://issuu.com/cedodal/docs/arqs I -Imb I-diario_ cr_tica-0 I- I2-43

Fiorito, M. (2012). El ejercicio del arquitecto en la administración pública: la Dirección General de Arquitectura (1 933-1944). II Jornadas de Investigadores en formación: Reflexiones en torno al proceso de investigación. Instituto de Desarrollo Económico y Social-IDES. Ciudad Autónoma de Buenos Aires

Flores, J. J. ( 8 de mayo de 2014). Una postal de la ciudad. Ecos Diarios, Necochea.

Gerchunoff, P.y Antúnez, D. (200 I). De la bonanza peronista a la crisis de desarrollo. En Torre, J. C. (Dir.). Nueva Historia Argentina. Tomo VIII: Los años peronistas (1943-1955) (pp. 125-205). Buenos Aires: Sudamericana.

Jajamovich, G. (20I I). Arquitectos proyectistas y transición democrática. Anales del Instituto de Arte Americano e Investigaciones Estéticas «Mario J. Buschiazzo», 4 I (2), 203-212.

Liernur, J. (200 I). Arquitectura en la Argentina del siglo XX. La construcción de la modernidad. Fondo Nacional de las Artes. Buenos Aires: Artes gráficas Corin Luna.

Liernur, J. F., Aliata, F., Crispiani, A. y Silvestri, G. (2004). Diccionario de Arquitectura en la Argentina. Buenos Aires: AGEA.

Montaña, E. (2008). Las disputas territoriales de una sociedad hídrica. Conflictos en torno al agua en Mendoza, Argentina. Revibec: Revista de la Red Iberoamericana de Economía Ecológica (9), I- 17.

Pabellón Argentino (1970, marzo). Nuestra Arquitectura (463), 35-37.

Pintus, A. H. G. (20 I4). Postales suburbanas. Arquitectura y suburbios residenciales en Argentina (1910-1940). Arquitectura, 8(3), 64-80. 
Piovani, J. I. (20 I 0). La observación. En Marradi, A.; Archenti, N. y Piovani, J. I., Metodología de las Ciencias Sociales (pp. 191-202). Buenos Aires: Emecé.

Quiroga,W. (20 I 2). Feria de América: vanguardia invisible. Mendoza: Fundación del Interior

Quiroz, R. (s.f.). Quiroz, Roberto. Moderna Buenos Aires. Recuperado de https:// www.modernabuenosaires.org/arquitectos/roberto-quiroz

Raffa, C. (dir.) (2017). Arquitectos en Mendoza. Biografias, trayectorias profesionales y obras (1900-1960). TOMO I, IHA-FFyL-UNCUYO. Ediciones Biblioteca Digital UNCUYO. Recuperado de https://bdigital.uncu.edu.ar/9327

Raffa, C. (2018) Turismo social: entres simbolismos y materializaciones. En Raffa, C., Hirschegger, l., Ortega, L., Cremaschi, V., y Durá Gúrpide, I., Proyectos y concreciones: obras y políticas públicas durante el primer peronismo en Mendoza $1946-$ 1955 (pp. 172-197). Mendoza: Universidad Nacional de Cuyo. Secretaría de Ciencia, Técnica y Posgrado. Recuperado de https://bdigital.uncu.edu.ar/ I 476

Raffa, C. (Dir.) (2019). Arquitectos en Mendoza. Biografias, trayectorias profesionales y obras (196 I-1972). TOMO 2, IHA-FFyL-UNCUYO. Ediciones Biblioteca Digital UNCUYO. Recuperado de http://bdigital.uncu.edu.ar/ I3376

Raffa, C. y Cirvini, S. (2013). Arquitectura moderna: autores y producción en Mendoza-Argentina (1930-1970). Arquitecturas del Sur, 3 I (43), 34-47. Recuperado de http://revistas.ubiobio.cl/index.php/AS/article/view/762

Raffa, C. y Marchionni, F. (20I I). El patrimonio efímero y la representación del trabajo: pabellones de exposiciones y escenarios vendimiales en Mendoza (Argentina), 1950-1955. Anales $9^{\circ}$ Seminario DOCOMOMO Brasil. Recuperado de https://docomomo.org.br/wp-content/uploads/2016/0 I/004_M27_OR-Elpatrimonio-efimero-y-la-representacion-del-trabajo-ART_cecilia_raffa.pdf

Sautu, R., Boniolo, P., Dalle, P. y Elbert, R. (2005). Manual de metodología. Buenos Aires: CLACSO (Campus Virtual).

Stake, R. E. (1998). Investigación con estudio de casos. Madrid: Ediciones Morata.

Torre, J. C. y Pastoriza, E. (200 I). La democratización del Bienestar. En Torre, J. C. (Dir.). Nueva Historia Argentina. Tomo VIII: Los años Peronistas ( 1943-1955) (pp. $257-$

312). Buenos Aires: Sudamericana.

Tres casas suburbanas (1945, marzo). Nuestra Arquitectura (I 88), 82-9|.

Verde, R. (2002). Brutalismo, Escola Paulista: entre o ser e o não ser. Porto Alegre: ARQTEXTO, 2(I), 6-3I.

Waisman, M. (1993). El interior de la Historia. Historiografia Arquitectónica para uso de Latinoamericanos. Bogotá: Escala.

Zevi, B. (1998). Saber ver la arquitectura. Ensayo sobre la interpretación espacial de la arquitectura. Barcelona: Ediciones Apóstrofe. 